\title{
Optical spectral reshaping for directly modulated 4-pulse amplitude modulation signals
}

Ozolins, Oskars; Da Ros, Francesco; Cristofori, Valentina; Pang, Xiaodan; Schatz, Richard; Chaibi, Mohamed E.; Bramerie, Laurent; Popov, Sergei; Galili, Michael; Oxenløwe, Leif Katsuo

Total number of authors:

12

Published in:

Proceedings:of the 19th International Conference on Transparent Optical Networks

Link to article, DOI:

10.1109/ICTON.2017.8024895

Publication date:

2017

Document Version

Peer reviewed version

Link back to DTU Orbit

Citation (APA):

Ozolins, O., Da Ros, F., Cristofori, V., Pang, X., Schatz, R., Chaibi, M. E., Bramerie, L., Popov, S., Galili, M., Oxenløwe, L. K., Peucheret, C., \& Jacobsen, G. (2017). Optical spectral reshaping for directly modulated 4pulse amplitude modulation signals. In Proceedings:of the 19th International Conference on Transparent Optical Networks (pp. 1-1). IEEE. https://doi.org/10.1109/ICTON.2017.8024895

\section{General rights}

Copyright and moral rights for the publications made accessible in the public portal are retained by the authors and/or other copyright owners and it is a condition of accessing publications that users recognise and abide by the legal requirements associated with these rights.

- Users may download and print one copy of any publication from the public portal for the purpose of private study or research.

- You may not further distribute the material or use it for any profit-making activity or commercial gain

- You may freely distribute the URL identifying the publication in the public portal 


\title{
Optical Spectral Reshaping for Directly Modulated 4-Pulse Amplitude Modulation Signals
}

\author{
Oskars Ozolins ${ }^{1}$, Francesco Da Ros ${ }^{2}$, Valentina Cristofori ${ }^{2}$, Xiaodan Pang ${ }^{1,3}$, Richard Schatz ${ }^{3}$, \\ Mohamed E. Chaibi ${ }^{4}$, Laurent Bramerie ${ }^{4}$, Sergei Popov ${ }^{3}$, Michael Galili ${ }^{2}$, Leif K. Oxenløwe ${ }^{2}$, \\ Christophe Peucheret ${ }^{4}$, and Gunnar Jacobsen ${ }^{1}$ \\ ${ }^{1}$ ACREO Swedish ICT AB, Kista, Sweden \\ ${ }^{2}$ DTU Fotonik, Technical University of Denmark, Lyngby, Denmark \\ ${ }^{3}$ KTH Royal Institute of Technology, Stockholm, Sweden \\ ${ }^{4}$ FOTON Laboratory, CNRS UMR 6082, ENSSAT, University of Rennes 1, Lannion, France
}

\begin{abstract}
The tremendous traffic growth in intra/inter-datacenters requires low-cost high-speed integrated solutions [1]. To enable a significantly reduced footprint directly modulated lasers (DMLs) have been proposed instead of large external modulators. However, it is challenging to use DMLs due to their low dispersion tolerance and limited achievable extinction ratio (ER). A promising solution to this problem is optical spectral reshaping (OSR) since it is possible to increase the dispersion tolerance as well as to enhance the achievable ER for both on-of-keying [2] and 4-pulse amplitude modulation (PAM) [3] signals. However, moving to 4-PAM,many of the impressive demonstrations reported so far rely heavily on off-line digital signal processing (DSP), which increases latency, power consumption and cost. In this talk, we report on (i) a detailed numerical analysis on the complex transfer function of the optical filter for optical spectral reshaping in case of pulse amplitude modulation and(ii) an experimental demonstration of real-time dispersion-uncompensated transmission of 10-GBd and 14-GBd 4-PAM signals up to 10- and 26-km SSMF. This is achieved by combining a commercial $10-\mathrm{Gb} / \mathrm{s}$ DML with optical spectral shaping, thus removing the need for any complex off-line DSP and improving dispersion tolerance. These achievements are enabled by OSR based on a passive microring resonator fabricated on the SOI platform [4]. Significant improvement in receiver sensitivities was observed for both a 10-GBd signal after 10-km SSMF transmission and 14-GBd with no penalty after 26-km SSMF transmission.
\end{abstract}

\section{REFERENCES}

[1] O. Ozolins et al.: $100 \mathrm{GHz}$ externally modulated laser for optical interconnects [Invited paper], J. Lightwave Technol., preprint, 2017.

[2] V. Cristofori et al.: Direct modulation of a hybrid III-V/Si DFB laser with MRR filtering for 22.5-Gb/s error-free dispersion-uncompensated transmission over 2.5-km SSMF, in Proc. ECOC, Düsseldorf, 2016, paper Th.2.P2.SC4.42.

[3] C. Yang et al.: IM/DD-based 112-Gb/s/lambda PAM-4 transmission using 18-Gbps DML, IEEE Photon. J., vol. 8, pp. 1-7, 2016.

[4] F. Da Ros et al.: 4-PAM dispersion-uncompensated transmission with micro-ring resonator enhanced 1.55- $\mu \mathrm{m}$ DML, in Proc. CLEO, California, USA, 2017, submitted. 